María Eloína García García

Universidad de Trieste

\title{
El tiempo en una novela nostálgica: La aldea perdida de Armando Palacio Valdés
}

Palabras clave: nostalgia, tiempo, espacio, cronotopo, idilio

La nostalgia es un estado de ánimo que se manifiesta por el dolor que uno experimenta al recordar hechos del pasado, muchas veces de manera idealizada. Esto es lo que ocurre en la obra de Palacio Valdés donde los habitantes de la aldea asumen el rol de plañidero colectivo recreándose, desde el primer capítulo hasta el último, en las bondades de «aquellos tiempos antiguos»; de este modo, la referencia continua al tempus fugit será el motivo que dará coherencia y cohesión a todo el discurso de la novela. «iQuién volviera a los veinte años!» (Palacio Valdés, 2007: 75)ำ dice don Félix a las mozas en la romería del Carmen, añadiendo irónico una líneas más abajo: «-Quítame cuarenta años de encima de los hombros, querida, y hasta que el gallo cante me tendrás dando vueltas como un trompo alrededor de ti... » (75). Así, y dado que la nostalgia genera recuerdos y que los recuerdos producen nostalgia, el tiempo será la magnitud física que permitirá al autor ordenar las secuencias de los sucesos justificando, de este modo, las emociones que embargan a los aldeanos y que el lector intuye por el tono profético ya desde las primeras líneas.

Los personajes sienten añoranza por motivos diferentes y lo manifiestan de modo diverso; todo depende de la edad, del sexo y, por supuesto, de la propia condición social. Para los ancianos, los nuevos bailes y las modas traídas de fuera suponen un paso más hacia la ruptura del idilio y lo expresan en cuanto tienen ocasión:

1 La edición de la que hemos extraído las citas es la de la colección Austral, Espasa Calpe (2007), con prólogo de Álvaro Ruiz de la Peña. A partir de ahora, dado que las alusiones a La aldea perdida serán muy numerosas, pondremos solamente la página. 
A algunos viejos se les saltaban las lágrimas recordando los tiempos de juventud». [...] ${ }_{-i}$ Éste es el baile antiguo, muchachos!... Así se bailaba en nuestro tiempo. Miradlo bien... Reparad los pasos... Eh, ¿qué tali... [...]. La moda que habéis traído de Langreo será muy linda, en verdad, pero a mí no me agrada, porque con tanto salto y tanto taconeo, más que bailando parece que estáis trillando la mies. (76)

Naturalmente, los jóvenes, recurriendo a un tiempo de menor alcance, añoran la complicidad y la dicha que proporcionaba el juego compartido cuando eran niños, y lo hacen también con locuciones propias del ámbito rural: «Amigos somos desde que ni tú ni yo levantábamos una vara del suelo y nos metíamos en los zarzales buscando nidos y cortábamos cañas de saúco para hacer tiratacos mientras nuestros padres aserraban algún haya para hacer madreñas» (62).

También el encabezamiento de la novela refleja ese sentimiento de desamparo; como bien decía Barthes (1973: 29-54) un título es un aperitivo ya que subraya la función de apertura y síntesis de la obra. La aldea remite a un espacio que, de manera simbólica, asimilamos a las propias raíces, y el participio del verbo perder enfatiza precisamente ese sentido, añadiendo las connotaciones de olvido y de distancia; así, ya desde el aperitivo, intuimos la importancia que tendrá en el relato la noción, doble e indisoluble, de tiempo-espacio. En general, los críticos, como recuerda Francisco Trinidad en el prólogo de su edición (Palacio Valdés, 2006: 11-45), creen que la pérdida mencionada en el título se refiere a la niñez del autor. Conviene recordar que este vivió su juventud y madurez en Madrid, lejos de Laviana, su tierra natal, por lo que no carece de fundamento esta última tesis. De hecho, en la introducción a La novela de un novelista, el escritor reflexiona sobre su experiencia vital en el exilio haciendo referencia explícita al tiempo y al espacio:

En verdad que no debo quejarme de mi hado. Hay sujetos que pasan su vida lamentándose de cuanto les rodea, de su patria, de su familia, de sus amigos, de su profesión y hasta del siglo que les vio nacer, del tiempo y del espacio. El hombre es un ser que quisiera estar siempre en otra parte. Yo no he aspirado a moverme de la mía. (Palacio Valdés, 2005: 44-45) 
Palacio Valdés condensa en la narración motivos y cronotopos ${ }^{2}$ propios de varios géneros (de aventuras, regionalista, realista, de costumbres, etc.). Los procedimientos de asimilación del tiempo y del espacio de la novela griega -de aventuras y pruebas-, por ejemplo, podrían fácilmente trasladarse a la obra, sobre todo en el capítulo XIX aunque con algunas variaciones: la huida de la pareja protagonista de la ciudad a la aldea se configura como el cronotopo del regreso a casa en un espacio de itinerario generador de obstáculos y de dificultades. En este caso no se tratará de tempestades o de personajes extraordinarios sino de la llovizna que obliga a los amantes aldeanos a guarecerse bajo corredores y hórreos, retrasando de este modo el tiempo de llegada a su destino y proporcionando a la historia el ingrediente romántico. En la huida, la tensión temporal viene marcada por numerosas locuciones adverbiales y oraciones breves en presente que contribuyen a recrear ese clima de misterio que exige la aventura; en definitiva, se trata de escenificar al modo clásico la incursión de la fatalidad en el relato:

Llueve de nuevo y de nuevo se refugian bajo el corredor de una casa. Por fin llegan a la Pola, siguen a Entralgo y para vadear el río, se ve necesitado Nolo a mojarse hasta la cintura, porque teme que el caballo resbale con los dos y dé con ellos en el agua. Así, montada sólo Demetria y llevando él a Lucero por el diestro, se salvan de un percance. Cuando tocan en las casas de Entralgo comienza a llover con violencia. Debajo del corredor emparrado de la casa del capitán se guarecen. Era ya cerca del amanecer. (283)

Podemos decir que, efectivamente, los indicios espaciales y temporales se han fusionado en este capítulo para crear ese cosmos particular de la novela de aventuras; pero los cronotopos no se configuran de manera completa sino que conviven y se alternan con otros. El marco geográfico de La aldea perdida no es inmenso como el de la novela griega de aventuras; en realidad se limita a una comarca y esto es así porque, al tratarse de una obra regionalista, comparte también el procedimiento de asimilación tiempo-espacio de la novela idílica, realidades que tienden a organizarse de modo armónico con la naturaleza. En el idilio, la continuidad vital de las generaciones se define gracias a la unidad de espacio, en palabras de Bajtín: «por la vinculación de la vida a las generaciones a un determinado lugar, del cual es inseparable esa

2 Bajtín (1989: 237-409) define cronotopo como «la conexión esencial de relaciones temporales y espaciales asimiladas artísticamente en la literatura». En la misma obra aporta, además, una clasificación detallada de los mismos. 
vida, con todos sus acontecimientos»; de igual modo, la unidad de tiempo «acerca y une la vida y la tumba, la niñez y la vejez, la vida de las diferentes generaciones que han vivido en el mismo lugar» (Bajtín, 1989: 376-377). De ahí que el centro neurálgico de la acción no exceda, en este caso, los límites de la región asturiana y que los dos amantes deseen regresar al lugar donde se encuentran sus raíces, biológicas y sentimentales respectivamente, y donde presumiblemente vivirán sus descendientes. Precisamente, en La aldea perdida se pone de relieve el valor que los personajes dan a ese sucederse de las generaciones como modo de perpetuar la propia identidad. Pongamos como ejemplo la descripción de la casa del capitán don Félix (punto de referencia de todo el pueblo) frente a la cual se celebra la romería, y que el narrador nos describe de esta forma:

La casa del capitán, que aquellos cándidos aldeanos solían llamar palacio, era un gran edificio irregular de un solo piso con toda clase de aberturas en la fachada: ventanas, puertas, balcones, corredores, unos grandes, otros chicos; de todo había. Parecía hecho a retazos y por generaciones sucesivas. $(64)^{3}$

La tendencia valdesiana a subrayar esa identidad popular noble, con sus virtudes ancestrales, queda patente en la insistente descripción del pasado: «La juventud de las cuatro últimas rivalizaba desde tiempo inmemorial en gentileza y en ánimo. De un lado, Entralgo y Villoria; del otro, Lorío y Condado» (54). No obstante, el idilio puede quebrarse cuando la familia pierde su capacidad de generar descendencia. Las enfermedades y la debilidad no son vistas con generosidad pues amenazan la continuidad en el tiempo de la propia raza. Tras la muerte de su hija, don Félix confiesa a la aldeana Flora que él es su verdadero padre, manifestándole la conveniencia de legalizar la situación, aunque no disimula en ningún momento su arrogancia aristocrática: «iBasta de tísicos!... Quiero que corra por mi descendencia sangre nueva y generosa, quiero morir rodeado de niños frescos, sonrosados» (271).

Por lo que se refiere al espacio de la casa, este cumple con todos los requisitos que podemos exigir al cronotopo idílico: es un mundo reducido pero autosuficiente (Dorca, 2004) donde las generaciones se suceden unas a otras y van organizando

3 Francisco Trinidad señala en su prólogo a La aldea perdida que una descripción similar aparece en La novela de un novelista, cap. II: «Era un gran caserón hecho a retazos por sucesivas generaciones» (Palacio Valdés, 2005: 55). Además, «la casa del capitán» es, en realidad, el caserón natal del mismo Palacio Valdés. 
el tiempo de las faenas del campo, de la casa y del ganado. Como muestra, nos remitimos a una de las referencias temporales más empleadas en la obra, relacionada con las épocas de traslado del ganado:

Porque el tío Goro poseía en aquellos campos, no lejos de la Braña, una cabaña con su establo y alrededor un prado cercado. Allí solía llevar parte de sus vacas en los meses de calor; pacían el prado y las hierbas pertenecientes a los pastos comunales del concejo de Laviana; retirábalas al llegar el mes de octubre. (79)

Todos los personajes asumen este lapso temporal como si se tratara de una estación completa (abril-octubre) con sus días de fiesta. Don Félix, por ejemplo, suele esperar con impaciencia la llegada del ganado que viene a «sacarle de su tristeza» en el mes de agosto:

[...] Este ganado no bajaba definitivamente a invernar hasta los primeros días de octubre, y estábamos en los de agosto, pero solían traerlo a Entralgo una vez durante el verano para que su dueño viese por sus ojos el estado en que se hallaba, y, si era necesario, dejar alguna res en casa o venderla. La entrada triunfal de aquel lindo rebaño, compuesto de cuarenta o cincuenta vacas con sus crías, era siempre un acontecimiento magno en la pequeña aldea. [...] la turba infantil de la población se estremecía [...]. (168)

Este tipo de labores diseña y organiza otras actividades proporcionando el ritmo cíclico a la novela. Jacinto, cumplidor y cabal, informa a Flora de que si no acepta el compromiso partirá en octubre con destino a América, eso sí, después de haber realizado todas sus tareas agrícolas: «Pues bien; en el mes de octubre, después que ayude a mi padre a cortar el maíz y sacudir la castaña, me embarcaré en Gijón y no me verás más ... inunca más! ... El pobre Jacinto allá morirá solo y sin consuelo... [...]» (192-193).

Probablemente, nuestro autor, al igual que Pereda -tal como señala Toni Dorca en su estudio (2004: 24)-, se dejó influenciar por las obras pastoriles del Renacimiento, como la de Fray Antonio de Guevara. En El menosprecio de corte y alabanza de aldea, este manifiesta su admiración por la forma de aprovechar el tiempo en el campo, para lo cual es imprescindible mesura e inteligencia, frente a la de la ciudad que, superficial y apresurada, no sabe gozar de tal privilegio. En el capítulo VI Fray Antonio sentenciaba: 
Es privilegio de aldea que los días se gocen y duren más, lo cual no es así en los soberbios pueblos, a do se pasan muchos años sin sentirlos y muchos días sin gozarlos. Como en el campo se pase el tiempo con más pasatiempo que no en el pueblo, parece por verdad que hay más en un día de aldea que no hay en un mes de corte. ¡Oh!, cuán apacible es la morada del aldea, a do el sol es más prolijo, la mañana más temprana, la tarde más perezosa, la noche más quieta, la tierra menos húmeda, el agua más limpia, el aire más libre, los lodos más enjutos [...]. El día de la ciudad siéntese y no se goza, y el día del aldea gózase y no se siente, porque allí el día es más claro, es más desembarazado, es más largo, es más alegre, es más limpio, es más ocupado, es más gozado; y finalmente digo que es mejor empleado y menos importuno. (Guevara, 1790: 90)

En esta misma tónica, Demetria, nostálgica de sus labores diarias, escribirá así a sus padres: «Cada día que pasa me acuerdo más de Canzana. ¡Qué vida tan descansada llevaba ahí, madre! ¡Cómo me gustaba ir al río a lavar la ropa y sallar con mis amigas el maíz, y por la noche hilar al par del fuego!» (245). En suma, lo que para algunos es tarea ardua para otros puede ser tiempo bien gozad $0^{4}$. Desde luego, la vida en la aldea fluye «lejos del tráfago y estruendo de las ciudades» (107) y una partida de cartas, como la del capitán don Félix y don Prisco, puede anudarse y durar veinte años porque lo que importa es el espacio del tiempo y no el fin ni la vil ganancia. Además, en la aldea el tiempo no pasa, se desliza ${ }^{5}$, porque hay espacio ${ }^{6}$ para todo, incluso para el ocio:

$\mathrm{Y}$, sin decirse otra palabra, ambos se introdujeron en la morada del capitán; subieron a su gabinete, encendieron un gran velón de dos mecheros, cerraron cuidadosamente la puerta, se sentaron a una mesa cubierta con tapete verde y, poniendo

4 En esta dimensión podemos incluir el tiempo psicológico (Benveniste, 1974). Antonio Garrido Domínguez recuerda en su trabajo sobre el texto narrativo que el tiempo no es sentido de la misma manera por todos (2009: 704-705), dando cuenta de la abundante fraseología popular en este sentido.

5 El verbo deslizar, bajo distintas formas, aparece a menudo en los escritos de Palacio Valdés (tanto en las novelas como en la correspondencia) para referirse al tiempo.

6 Es frecuente en la obra el empleo de tener o baber espacio por tener o baber tiempo: «Cuando se vio lejos de las iras de su amo, sin dejar de exhalar gemidos lastimeros, tuvo espacio para reflexionar» (269). Abunda también la expresión adverbial por espacio de + boras, minutos, instantes, etc. $(69,234,265$, etc.) tan común todavía en el habla del ámbito rural asturiano y que se recrea en esa doble noción -locativa y temporal- del término. 
sobre él una baraja, anudaron la partida de brisca que hacía ya más de veinte años tenían comenzada. (77)

En una de las numerosas discusiones sobre la pérdida de esa condición idílica, el señor de las Matas recuerda a don Félix que Laviana está a punto de sufrir la contaminación propia de la ciudad, contraponiendo de nuevo el pasado al presente: «[...] no eres hombre de estos tiempos. Debiste nacer en las montañas de la Arcadia feliz, y dejar que tu vida se deslizase lejos del tráfago y estruendo de las ciudades, sonando el dulce caramillo y rindiendo culto a Pan y a las ninfas, coronada la frente de mirto y roble» (106-107). Por otra parte, se presenta con frecuencia esa diferencia de óptica al medir el tiempo en ambos espacios. Antes de la llegada de Nolo a la capital en busca de su novia, el narrador lo computa en función de los fenómenos naturales, de las actividades domésticas o de las comidas y no del reloj. En el espacio urbano, la expresión cambia radicalmente: «Cuando dio vista a Oviedo eran bien sonadas las diez de la mañana» (273). Comprensiblemente, la angustia de la espera no deja otra opción que el reloj para imprimir la tensión temporal:

Una hora de espera. No se atrevió a meterse en el portal, porque de cuando en cuando todavía llegaba algún tertulio. Pero sonaron las once y como hacía ya rato que nadie acudía, decidió colocarse a la puerta como le ordenaron. Sonaron las once y media; las doce menos cuarto. Nada. La impaciencia de Nolo iba degenerando en tristeza profunda. (280)

Horas más tarde, al llegar de nuevo a la aldea con Demetria, el tiempo recobra su valor sublime y poético, ligado a la medida no artificial del mismo: «[...] una débil claridad comenzaba a esparcirse por el oriente» (284).

El artilugio para calcular el tiempo es cosa de ricos, de nobles o propio de costumbres demasiado avanzadas que podrían romper la vida idílica y armónica. Pedro Regalado, el mayordomo, sabe que algún día poseerá el codiciado objeto; la cadena ya la tiene: «Su traje no era de aldeano ni de caballero: chaqueta de pana, pantalón largo, botas altas y sombrero de fieltro; colgando por encima del chaleco, una gran cadena de plata para el reloj» (65); ahora bien, el reto en la romería del pueblo, que consiste en lanzar la barra lo más lejos que uno pueda, tendrá como premio, precisamente, un reloj de noble material: «-Llegó el momento, mozos valerosos, de que probéis vuestra enjundia delante de las hermosas de Entralgo. Mi amo don Félix me ha entregado este reloj de plata, 
con su cadena, para que se lo regale al tirador que más lejos clave la barra de hierro de quince libras» (131).

Por otra parte, poseer un reloj no es un privilegio que merezcan todos: «-¡Bendita sea tu sandunga! ¿No te parece, Plutón, que ha hecho bien la morenita en negarse a dar el reloj a ese palurdo? -dijo uno de los mineros de la boina colorada a otro de sus compañeros» (134).

Sin embargo, Don Félix sí puede medir el tiempo de una manera precisa, cabal y armónica, como corresponde a su raza:

Don Félix Cantalicio Ramírez del Valle descansaba en la fortaleza blindada que tenía por dormitorio pocos días después del suceso que acabamos de narrar. Habían sonado ya las dos de la noche en el reloj con música del salón de arriba; se hallaba en la cama desde las once, y, sin embargo, sólo había logrado echar un sueñecito de media hora. (161)

Sin duda, la llegada de las minas es nociva para los jóvenes de Laviana y favorece la ruptura del idilio, hasta el punto de que el narrador sitúa casi en el mismo plano delictivo la posesión de una navaja y la del preciado mecanismo: «No solamente cambiaron su pintoresco traje aldeano por el pantalón largo y la boina, sino que se proveyeron casi todos de botas de montar, bufanda, reloj y, lo que es peor, de navaja y revólver» (249).

El narrador se deja contagiar, asimismo, por ese modo particular de asumir el paso del tiempo en el ámbito rural. Cuando se refiere a las edades de los personajes se muestra cauteloso, ignorando a menudo el carácter omnisciente de su propia voz narrativa: de Goro dice que «frisaba en los cincuenta» (93); de Maripepa cuenta que «Era ésta una mujer de cuarenta años lo menos, fea, coja, desdentada $[. .] ».(66)$; de Pedro Regalado apunta que «tenía de treinta y cinco a cuarenta años de edad» (65) y que su mujer «tenía alguna edad más que él» (69). Sin lugar a dudas, la huella que deja el paso del tiempo en los cuerpos es la vara de medirlo y Palacio Valdés no es ajeno a esta costumbre, de ahí las expresiones tendentes a matizar los crudos números. De Ramírez del Valle, por ejemplo, señala que «no había cumplido cuarenta años ni representaba más de treinta» (66) y que al capitán don Félix «podría juzgársele por hombre de cincuenta años, aunque pasaba bien de los sesenta» (72); además, impulsado por la comprensible empatía con el personaje, añade: «No pasan días ni años por él» (173).

En otro orden de cosas, podemos añadir que las acciones se desarrollan en lugares reales y fáciles de identificar - pueblos del concejo de Laviana, 
caminos, castañares, zonas de pastos de montaña reconocibles en el mapa actual y espacios urbanos de la capital- y en un tiempo crónico que se presenta a todas luces como realista. Nos referimos con ello al que tardan los personajes en ir de un lugar a otro, considerando la verticalidad u horizontalidad de los espacios, la climatología, la velocidad alcanzada por los caballos, el peso, los obstáculos ${ }^{7}$, etc.

El relato se construye en el marco de la analepsis que cubre un año de la niñez del narrador. La historia comienza la víspera de Nuestra Señora del Carmen de Entralgo y concluye un año y un día después; además, gracias a algunos indicios, como las expropiaciones de terrenos en la zona y una revista, El Eco de Asturias, que se mencionan en la novela, podríamos situar el segmento temporal de la historia entre 1868 y 1891.

El prólogo viene a ser una invocación de tono apocalíptico y el último capítulo se abrirá con una reflexión sobre el estado físico y anímico del relator: «Voy a terminar. La tarde declina, y mi mano cansada se niega a sostener la pluma [...]» (314). La exhortación inicial se condensa en una frase: «La Arcadia ya no existe. Huyó la dicha y la inocencia de aquel valle» (47). Por su parte, el capítulo XXII se cierra con estas palabras: «-Decís que ahora comienza la civilización... Pues bien, yo os digo..., ¡oídlo bien! ..., ¡yo os digo que abora comienza la barbarie» (319). Dos adverbios: ya y abora, uno resultativo y otro en apariencia incoativo, configuran dos sentencias similares o, por lo menos, así resultan a ojos del lector después de haber leído la novela. Lo que aparecía como una inquietud premonitoria en la invocación se constata como una realidad trágica en las últimas líneas. Además, el deíctico aquel nos reafirma en la idea de que existe una gran distancia temporal y espacial entre el autornarrador y Laviana y que, ya al comienzo de este trabajo, poníamos de relieve al hablar del título y de la nostalgia.

El discurso de la voz narrativa registra varias perturbaciones curiosas a lo largo del relato, y los recursos de los que se vale la misma para manipular el tiempo van desde las analepsis, con valor explicativo, hasta las prolepsis a modo de profecía. A veces anticipa lo que va a ocurrir, bien usando los

7 En el capítulo XIX, los protagonistas hacen el recorrido de Oviedo a Laviana en siete horas. Teniendo en cuenta que la distancia entre la ciudad y la aldea es de treinta kilómetros, y que la velocidad aproximada que alcanza un caballo (con dos personas a lomos del mismo y algunos obstáculos en el camino) difícilmente alcanza los cuatro $\mathrm{km} /$ hora, creemos que se trata de una escenificación bastante realista. Nolo, el protagonista, en el recorrido inverso, por la mañana, había empleado la mitad de ese tiempo, claro que entonces iba solo y ligero a lomos de Lucero. 
tiempos hipotéticos, bien haciendo uso de perífrasis ingresivas, o simplemente empleando las formas canónicas de futuro. En el capítulo IV, el señor de las Matas, intuyendo cercanas las expropiaciones de terrenos agrícolas, anuncia drásticamente: «El día que escuche subir por los castañares de Carrió los pitos [...] será el día más triste de mi vida»(105-106). En el capítulo VI, el día de la romería, por la noche, en el lagar de don Félix, donde se «debatía la cuestión de las minas» (143), el narrador da forma al presagio apoyándose en los sentimientos que embargan a los labradores. Tal vaticinio se expresa, en este caso, con una perífrasis y un tiempo hipotético con valor de futuro: «El mundo antiguo, un mundo silencioso y patriarcal que había durado miles de años, iba a terminar, y otro mundo, un mundo nuevo, ruidoso, industrial y traficante, se posesionaría ${ }^{8}$ de aquellas verdes praderas y de aquellas montañas» (143). En el capítulo XVII, ya en invierno, se cumple la intuición de los personajes con una sorprendente locución exclamativa que nos deja un poco perplejos pues la postura del autor había sido, hasta el momento, contraria a la profanación del paisaje:

Por fin silbó, sí, silbó la locomotora (¡Dios la bendiga!) por encima de Entralgo. Cruzó soberbia, abriendo enorme brecha en los castañares que lo señoreaban, taladró con furia a Cerezangos, aquel adorado retiro del capitán, y siguió triunfante, vomitando humo y escorias, hasta Villoria. (216)

Las retrospecciones servirán para presentarnos a los personajes y configurar sus historias o caracteres; a veces este proceso se desarrolla de forma caótica, proporcionando desviaciones temporales interesantes. El caso más original es el que remite a los inicios de la relación amorosa de Nolo y Demetria, donde se aborda la descripción analéptica del verano anterior, que a su vez inserta otro flasbback relativo al invierno que precedía a esa misma estación:

Pero al acercarse el verano en el año anterior, Demetria, que cumplía catorce, experimentó grandiosa transformación. La niña, de formas graciosas pero indecisas, se convirtió durante aquel invierno en una joven de elevada estatura, de gallarda y noble presencia. Nolo quedó sorprendido y confuso al verla. (81)

Unas líneas más abajo, tejiendo su relato desordenado, el narrador regresa al otoño:

8 La cursiva de las citas en esta página es nuestra. 
Poco a poco, el deseo de verla se fue convirtiendo en anhelo, luego en afán irresistible. No sabía lo que le pasaba, ni tenía alientos para trabajar ni para divertirse en las romerías. Dejaba transcurrir el tiempo tumbado sobre el césped mirando pacer el ganado o acariciando distraído la cabeza del mastín. Por fin llegó el otoño. El tío Goro retiró sus vacas. Nolo no pudo resistir más. (82)

La presencia del camino se manifiesta en condiciones muy diferentes a lo largo de la obra. En ocasiones, se trata de un recurso básicamente funcional y en otras, sin embargo, se convierte en una alegoría en la que, como veremos más adelante, el hombre elige un camino y no otro, lo que representará, a fin de cuentas, la predilección por la vida bucólica. Por ejemplo, en el capítulo I, el autor asturiano nos presenta a tres personajes que van caminando entre castañales, cuesta arriba, un sábado, quince de julio, víspera de la romería del Carmen. La intención de los mozos es la de llegar a la Braña ${ }^{9}$, donde vive Nolo con su familia. Hace calor y se paran a menudo para «reposar un instante» (54). La subida es penosa, pero la voz narrativa nos aclara que han elegido el camino arduo (lo que implica dilatación en el tiempo) «para guardarse de las miradas de los indiscretos» (52) aunque, en realidad, se trata de una sutil estratagema para que los personajes se presenten a sí mismos en un escenario tácticamente apropiado.

El salto al pasado se produce de manera similar en los tres casos: Celso, personaje que reniega de sus raíces asturianas, interviene en un contexto dialógico para recordar sus aventuras un año atrás, mientras hacía el servicio militar en Andalucía, poniendo de manifiesto así todos sus defectos lo cual se percibe por la reacción de incredulidad de los otros jóvenes. El narrador concluye su ejercicio rememorativo con una parcial e irónica alusión metalingüística: «A Celso se le hacía la boca agua contando estas aventuras románticas, y las enjaretaba una tras otra sin dar paz a la lengua» (56). Bartolo, en voz alta también, evoca sus batallas épicas contra los mozos de otros pueblos; la reacción de sus compañeros nos lleva a diseñar un carácter prevalentemente fanfarrón y cobarde. El alcance de ambas anécdotas es de un año y la duración de las mismas de apenas unas horas.

Cuando los tres jóvenes llegan a la Braña, Palacio Valdés condensa de modo sumarísimo los treinta años de trabajo y de prosperidad -hábilmente

9 La voz braña hace referencia a los pastos de montaña en Asturias y Cantabria. En la novela, el término se encuentra escrito con mayúscula ya que se trata del topónimo referido a un paraje poblado. 
simbolizados en la dura y tortuosa culminación del camino- del padre de Nolo. La síntesis extrema de la vida de Pacho sirve de contrapunto a la bonanza alcanzada por el mismo personaje a lo largo de sus años de esfuerzo y sudor aunque, desde el enfoque narrativo, la historia es relativamente marginal. Bal señalaba lo siguiente a propósito de este recurso rítmico: «[...] el resumen es un instrumento perfecto para presentar información de fondo, o para conectar varias escenas»; estrategia que contrasta, ciertamente, con lo que él mismo denomina «deceleración rítmica» (Bal, 2006: 81-83) ${ }^{10}$. Un resumen funcional de similares características, lo tenemos en el descenso de la montaña, por la tarde, que se remata en dos líneas genéricas al inicio del capítulo II: «Cuando los diputados llegaron a Entralgo el sol había traspuesto ya las colinas por el lado de Canzana» (64). A Palacio Valdés el descenso, mucho más rápido, y con frágil coyuntura táctica para el diálogo entre los mozos, ya no le interesaba desde el punto de vista descriptivo.

En el capítulo $\mathrm{X}$, sin embargo, Jacinto prefiere dar un rodeo por el camino llano, tal como aclara el narrador «para ganar tiempo» (198), aunque en este caso la locución no se interpreta como la voluntad de llegar antes, sino todo lo contrario: el mozo está radiante y pletórico por la respuesta de Flora a sus requerimientos y necesita contar su felicidad; además, reconoce que la tarea de la narración no solo precisa tiempo holgado sino también espacio generoso, aunque el espacio de la escritura ocupa, en este caso, apenas unas líneas:

Jacinto marchaba con paso ligero hacia Fresnedo por el camino llano de Entralgo, en vez de tornar por el monte como había venido. Era más largo, pero no tenía prisa de llegar a casa. Su corazón necesitaba narrar su dicha a los árboles y al río, al valle y a los montes, a la luna y a las estrellas. Y como adivinaba que la tarea iba a ser larga, procuró dar un rodeo para ganar tiempo. Marchaba cantando, y mientras cantaba iba recordando, y mientras recordaba iba soñando despierto. (198)

La novela tiene un aliado muy útil en las romerías, celebraciones que se dan en áreas abiertas y que marcan los tiempos, generalmente colectivos, de la obra. Las fiestas religiosas establecen el tiempo de las acciones y constituyen el andamiaje de lo que Bajtín define como cronotopo folclórico:

10 El capítulo XV, «Carta de Demetria», es un claro ejemplo de deceleración. Las reflexiones previas a la lectura de la misiva, las introspecciones, las reacciones de los lectores, producen un cambio de ritmo que se contrapone claramente a los resúmenes extremos que Palacio Valdés hace de algunos episodios. 
Un sentido fuerte y diferenciado del tiempo sólo pudo aparecer sobre la base del trabajo agrícola colectivo. En esta fase, precisamente se formó el sentido del tiempo que está en el origen de la formación y división del tiempo social: el de la vida cotidiana, de las fiestas, de los ritos ligados al ciclo de los trabajos agrícolas, de las estaciones, de los períodos del día, de las fases de crecimiento de las plantas y animales. (Bajtín, 1989: 358)

Efectivamente, los hechos importantes ocurren en los días de fiesta, en las vísperas y en los días sucesivos a las celebraciones. La historia da comienzo «un sábado del mes de julio, víspera de la romería del Carmen» (52). En esta ocasión, el narrador nos presenta a los personajes, lo que nos permite ir delineando la historia y lo que se avecina. En la romería de agosto, Demetria descubre que su familia natural no es la de la aldea sino que pertenece a una clase social alta de la capital. Al día siguiente, la protagonista se despide de Nolo para trasladarse a Oviedo con su madre biológica. Monótonas en la urbe y bucólicas en la aldea, se deslizan lentamente las estaciones (otoño e invierno) que, sin embargo, son referidas con sospechosa parquedad. Por fin, alcanzamos la fiesta de la Ascensión, fecha en la que el protagonista viaja con su jaco a la ciudad con la ilusión de encontrar a su amada Demetria.

En la romería del Carmen (un año más tarde), el autor se vale de una retrospección de breve alcance y de escasas líneas para centrar el interés en el evento religioso y no en la boda de los protagonistas como sería natural: «Era llegada de nuevo la fiesta de Nuestra Señora del Carmen. Dos días antes se había celebrado en la pequeña iglesia de Entralgo la unión de Jacinto y Flora, de Nolo y Demetria» (314). El narrador elude un episodio importante ya que su intención es la de focalizar el interés no en el elemento idílico sino en el evento simbólico: la romería. En ella, Demetria, diosa de la agricultura, muere a manos de Plutón, rey de los infiernos, o lo que es lo mismo en este caso: de la minería. En resumidas cuentas, el autor consigue escenificar a modo de tragedia griega el cumplimiento del presagio inicial. El idilio se rompe definitivamente y la historia de su Arcadia feliz sella la ficción con estas palabras: «[...] ahora comienza la barbarie» (319).

\section{Conclusión}

Todos los tiempos están representados en la novela: el físico, el psicológico, el filosófico y, obviamente, el lingüístico. El estado anímico de los habitantes de 
la aldea ante el premonitorio cambio de fortuna es el motivo que cohesiona la obra de Palacio Valdés. Los personajes viven obsesionados por un pasado que intentan recuperar a través de la memoria, proyectándose hacia un futuro que se intuye poco halagüeño y que, en las últimas líneas, se revela como trágico. Para dar forma a este sentimiento colectivo el autor se vale de motivos y cronotopos de distintos géneros pero, indudablemente, el idílicopastoril será el que conforme mayoritariamente esta novela regionalista. Las retrospecciones secundarias tienen valor justificativo y, en ocasiones, van insertadas sin ningún tipo de bisagra rememorativa. Por otro lado, los espacios elegidos para ubicar las acciones dan cuenta del conocimiento y de la experiencia del autor que los utiliza como escenarios meramente tácticos o con alguna intencionalidad metafórica.

Por lo que se refiere al tiempo lingüistico, no estaría de más reproducir aquí las palabras de Garrido Domínguez que, basándose en la doctrina de Benveniste, señala:

El tiempo se instaura cada vez que un hablante se apropia del código de la lengua para satisfacer sus necesidades comunicativas. Así pues, en cuanto el hablante dice Yo y se instala en la lengua funda el tiempo de la enunciación, el presente, que puede coincidir o no con el del enunciado. [...] el presente es la dimensión fundamental y desde ella se miden las otras dos: pasado y futuro (lo que ya no está presente, lo ya vivido, y lo que va a estarlo). (Garrido Domínguez, 2009: 705706)

Naturalmente, el presente convulso del narrador de La aldea perdida es el eje alrededor del cual se configuran el pasado y el futuro y, en consecuencia, el que dará forma fabulada a ese sentimiento nostálgico presente en toda la novela.

\section{Bibliografía}

Bajtín, M. (1989): Las formas del tiempo y del cronotopo en la novela. En: Teoría y estética de la novela. Madrid: Taurus.

Bal, M. (2006): Teoría de la narrativa. Madrid: Cátedra.

Barthes, R. (1973): «Analyse textuelle d'un conte d'Edgar Poe». En: Claude Chabrol (ed.), Sémiotique narrative et textuelle. París: Larousse. 
Benveniste, E. (1974): Problèmes de linguistique générale II. París: Gallimard.

Brugiatello, V. (2009): La relazione tra linguaggio ed essere in Ricoeur. Trento: UNI Service.

Dendle, B. J. (1993): «Diez cartas inéditas de Armando Palacio Valdés a Edmund Gosse y a William Heinemann». En: Boletín del Instituto de Estudios Asturianos, 47, 141, 303-313.

Dorca, T. (2004): Volverás a la región. Madrid: Iberoamericana.

Garrido Domínguez, A. (2009): El texto narrativo. En: El lenguaje literario. Vocabulario crítico. Madrid: Síntesis.

Genette, G. (1972): Figures III. París: Éditions du Seuil; trad. it. Figure III (1976). Torino: Einaudi.

Grosser, H. (1985): Narrativa. Milano: Principato.

Guevara, A. de (1790): Menosprecio de corte y alabanza de aldea. Madrid: Imprenta de Pantaleón Aznar.

Levinas, E. (1979): Le Temps et l'Autre. París: PUF; trad. it.: Il Tempo e l'Altro (1987). Genova: Il Melangolo.

Lorenzo Álvarez, E. de, Ruiz de la Peña, Á. (eds.): Palacio Valdés: un clásico olvidado (1853-2003); Actas del I Congreso Internacional Armando Palacio Valdés: un clásico olvidado. Entralgo-Laviana, 24-26 de septiembre de 2003. Laviana: Ayuntamiento de Laviana, 2005.

Martín Morán, J. M. (2004): «El espacio en la novela regionalista. El caso de La aldea perdida de Armando Palacio Valdés». En: Artifara, 4: http://www. cisi.unito.it/artifara/rivista4/testi/aldea.asp (06-02-2012).

Palacio Valdés, A. (1917): Páginas escogidas. Madrid: Calleja.

Palacio Valdés, A. (2005): La novela de un novelista: escenas de la infancia y adolescencia, Francisco Trinidad (ed). Laviana: Centro de Interpretación Palacio Valdés.

Palacio Valdés, A. (2006): La aldea perdida. Novela-poema de costumbres campesinas. Francisco Trinidad (ed.). Laviana: Centro de Interpretación Palacio Valdés.

Palacio Valdés, A. (2007): La aldea perdida. Madrid: Espasa Calpe.

Ricoeur, P. (1998): Passato, Memoria, Oblio. En VV. AA., Filosofia del tempo. Milano: Bruno Mondadori. 


\section{María Eloína García García}

University of Trieste

\section{Time in a nostalgic novel: La aldea perdida by Armando Palacio Valdés}

Keywords: nostalgia, time, space, chronotope, idyll

La aldea perdida is a regionalist novel dealing with a theme recurrent in $19^{\text {th }}$ century literature: transformations in social life and the environment of the valleys of the north of Spain in the wake of industrialization. The Asturian author sketches a portrait of happy rural life being menaced by the violent arrival of mines and miners. In this work we try to point out the strategies Valdes uses in order to tell a story in which, more than ever, time and space are intertwined to such an extent that nostalgia cripples the inhabitants. We see how time can be lived in different ways, according to the subject who is dealing with it or, conversely, suffering from it. We also point out how time spent days, hours and minutes - can be interpreted in different ways depending on the emotional situation, daily commitments or social condition of characters. We try to investigate all aspects of the concept of time, its nuances and the philosophical and narration tools Valdés uses in order to suggest a path leading nowhere else than to the traumatic nostalgia of the "lost hamlet". 